\title{
ÚLTIMA CITA CON BOB DYLAN
}

\author{
Mario Valdovinos
}

Las páginas que siguen presentan una crónica del derrumbe de un mito para cederle el paso al hombre real, al creador alucinado que contribuyó no a la caída de América sino a su persistencia. Desde la perspectiva de un fan tenaz de las canciones de Bob Dylan y seguidor de su extensa y compleja trayectoria artística, Mario Valdovinos revisa las etapas por las que el poeta-cantante ha pasado. El relato no excluye la crítica ni la ironía orientadas a desentrañar las profundidades de un mito que Dylan ocultó y tergiversó en sus primeras etapas como cantante, pero que hoy, en un momento de madurez y reconciliación consigo mismo, suaviza y devela (en especial con la publicación de sus Crónicas, 2005), a propósito de la cercanía de los años finales, los del momento de retirarse y colgar la guitarra, o quizás los de una nueva reinvención. El recorrido comienza con la actuación del cantante, en marzo de este año, en el teatro Arena de Santiago de Chile, donde se verificó una última cita con Bob Dylan.

Mario Valdovinos. Escritor, profesor de lenguaje y literatura en The Grange School y en la Universidad Finis Terrae, Santiago de Chile.

Estudios Públicos, 110 (otoño 2008). 
"No iba en busca de dinero ni amor". Bob Dylan, Crónicas I.

\section{$\mathrm{E}$} el momento en que fue anunciada la segunda visita de Bob Dylan a Chile, se dio inicio al show de su gira sudamericana que comenzó en México y después saltó a Argentina. El escenario: teatro Arena, en el centro del parque O’Higgins, tal vez el mejor de la capital. No hubo teloneros distractores ni pantallas gigantes, tampoco desbordes a la salida, apenas, en algunos temas clásicos, un inofensivo aire a marihuana y su exclusiva y eléctrica presencia, acompañada de cinco músicos cuyo look, todos de gris, contrastaba con el del líder de la banda, entero de negro, con botas texanas y pantalones con una cinta roja en los costados. Llevaba sombrero, de estilo más andaluz que de cowboy, como acostumbra, y a la distancia se advertía poco su rostro delgado y envejecido, mucho menos los bigotillos de cantante de boleros, estilo Leo Marini, que luce hace un tiempo.

La verdad, ese look resulta poco glamoroso y lo aleja de un rockstar, si bien — queda muy claro- corresponde a sus raíces, el folk, la música country, los huasos gringos, aunque dejó hace rato la guitarra acústica y la armónica como únicos acompañamientos de sus canciones.

En este sentido, Dylan, con todas las vueltas de campana que se ha dado en lo artístico y en lo ideológico, ha seguido fiel a sus orígenes, transmutándolos y llevando al esplendor la fusión entre el rhythm and blues, el country and western, las referencias bluseras, las baladas y el rock, eléctrico y pesado. Hasta este momento de sus numerosas metamorfosis excluye el jazz, pero no sería raro que fuera la sorpresa de la etapa final. "Me gustaba mucho el jazz moderno, me gustaba escucharlo en los clubes... pero no me mantenía al día ni estaba metido en él”, señala en su libro autobiográfico Crónicas $\mathrm{I}^{1}$.

El momento previo a la actuación me resultó impactante; ya que no soy demasiado asiduo a recitales, asisto sólo cuando es imprescindible la cita con la nostalgia y el asunto se vuelve un ajuste de cuentas con los años pasados, por ejemplo, Paul Mc Cartney y Joan Manuel Serrat. O, en los setenta, el legendario concierto ofrecido por el músico indio Ravi Shankar, al que me colé porque no tenía dinero para la entrada y del que regresé, desde el teatro Caupolicán a mi casa en la Gran Avenida, caminando y en estado de felicidad total.

${ }^{1}$ Dylan, Bob: Crónicas, Vol. I (Barcelona: Global Rhythm Press, 2005). 


\section{Otras voces, otros ámbitos}

Puede animarme también la curiosidad por ver a un artista al que sé vigente $\mathrm{o}$, en otros casos, lo opuesto, la constatación perversa de que me integraré a la tarea de esparcir un poco más sus cenizas.

La verdad, este último, era un poco malignamente mi estado anímico al asistir al show. Fui a la primera presentación, en abril de 1998, en el incombustible teatro Caupolicán, y lo que más me impresionó fue la frialdad del cantante para con el público. Interpretó cerca de quince canciones, no retornó a escena tras los aplausos, tampoco saludó, ni dijo un par de frases de rigor sobre el país al que había llegado por primera vez; ni menos concedió bonus alguno, por supuesto no presentó a sus músicos, en esa oportunidad los guitarristas Bucky Buxter y Larry Campbell, Tony Garnier, contrabajo, y David Kemper, batería, y, ni pensarlo, se despidió de la audiencia. Entró, cantó y desapareció. ¿Venció? Quedé, en esa oportunidad, con la sensación de que lo tomó como un ensayo general sin parar y sin público. — “Sigamos, guys, salga como salga”, parecía haberles dicho en los camarines a los componentes de la banda.

Sabía de la apatía legendaria de artistas, compatriotas suyos, cuyo cénit lo alcanzó Miles Davis, que llegó a tocar la trompeta de espaldas a los espectadores. De hecho, era una de las características que quería comprobar en vivo cuando el creador del cool jazz anunció visita al Flandes indiano, allá por 1990, al estadio Chile (hoy Víctor Jara). Pero nunca llegó porque el pájaro negro Miles debía emprender el vuelo final.

Dylan encarnó, y aún hoy encarna, tal vez a su pesar, el sueño americano a cabalidad. Arrancó de un hogar convencional, sin demasiada locura, extravagancia, vuelo ni horizontes, con un padre inmigrante judío, de origen ruso, comerciante y jodío, para probar suerte en Nueva York, específicamente en el Greenwich Village, el barrio de moda por los sesenta, donde vagaban los beatniks y derramaba su lírica torrencial Allen Ginsberg. Esa área urbana cobijó y vio pasar a buena parte de la oleada beat, a sus poetas, biógrafos y novelistas, como Jack Kerouac, William Burroughs, Gregory Corso, Lawrence Ferlinghetti, Neal Cassidy, algunos de irradiación local y, a la hora de las sumas y las restas, claramente sobrevalorados; mas Dylan, perteneciente a la misma camada de artistas, alcanzó fama universal transformándose en la figura epónima de la generación. Allí se vincula con Pete Seeger, con Joan Báez y se sabe que teloneó al mítico blusero John Lee Hooker. Andaba a la siga de su destino, si regresaba derrotado del sueño artístico y de la aventura de la fama podía dedicarse a ordenar las estanterías del negocio paterno y atender a los clientes, como hizo en una de sus 
apariciones cinematográficas, el filme "Pat Garrett y Billy the Kid”, de Sam Peckinpah (1973), donde encarna, en un papel secundario, al personaje llamado Alias. Sin embargo, su rol más importante estuvo en la composición y ejecución de la banda sonora.

Reitera en su escrito autobiográfico, Crónicas I (2005), que, si bien por vocación y aptitudes se dedicaba a la música, andaba un poco al garete, abierto a lo que viniera y se le presentara.

Como (pen)última encarnación del sueño americano, Bob — cuyo apellido artístico habría sacado, se dice, de la lectura tenaz del Rimbaud galés, Dylan Thomas, el mismo poeta que leía obsesivamente en el metro parisino Johnny Carter, el saxofonista negro, alter ego de Charlie Parker en el cuento "Las Babas del Diablo", de Julio Cortázar-, fue the right man in the right place. Algo había en el clima espiritual y cultural de esos años que Bob Dylan expresó a veces con vehemencia y otras con algo aún más penetrante: la melancolía. Allí está el testimonio de sus canciones grabadas en los primeros álbumes, “Bob Dylan” (1962), “The Freewheelin Bob Dylan” (1963), “The Times They Are a Changing” (1964) y "Highway 61 Revisited” (1965). Sus temas pueden entenderse como retazos de las atmósferas de su natal Duluth, Minnesota, donde nace el 24 de mayo de 1941; de Hibbing, el pueblo minero cercano a la frontera con Canadá hasta donde se traslada su familia, del clima presente en los distritos neoyorquinos y de los atardeceres color púrpura de Times Square. Se lanzó porque nada podía perder, nadie lo vería desembarcar en la unánime noche. Never mind, nunca se ve la misma cara dos veces en el río del subway. Así lo expresó Enrique Lihn en un poema de su libro A Partir de Manhattan, escrito a fines de los setenta.

El centro del mundo también puede ser un lugar donde, en cierto sentido, no pasa nada. Entonces, era preciso provocarlo, suscitarlo, echar a rodar la cabeza, desgajada del cuerpo, por las aceras de Nueva York donde en los locales nocturnos se anunciaban recitales del cantante. Música para outsiders, desambientados, seres en perpetuo desasosiego que buscaban algo, como él, y verían reflejado en esa guitarra y en esa voz lo que eran.

Por esos andurriales comienza su proximidad con las drogas, al parecer conditio sine qua non en USA para entrar al mundo artístico y permanecer en él: pitos, anfetaminas, pastillas, hondas aspiraciones de un aspirante a asceta. Situación que brilla por su ausencia en sus Crónicas, el libro de memorias publicado por el cantante en 2004 (2005).

Allí se gesta la leyenda, extensa e intensa, en los clubes y pubs, la hagiografía, la vida de un santo al revés, un vividor alucinado que desea gritar lo que siente sobre ese mundo. Y de allí también el cartel colgado de su cuello, por la prensa, que durará décadas: cantante protesta. Nada se 
pierde con vivir y cantar, aquí tienes un cuerpo a tu medida, hecho, como todos, en sombra, por amor a las artes de la carne, esmirriado, narigón, de contextura aparentemente débil, crespo y con esa blancura que se parece a la inocencia sin serlo. Escasa barba y de voz poco agraciada, pero con un vértigo en los dedos para tocar piano, guitarra, armónica y una capacidad desbordante destinada a guardar en su cerebro y en su corazón escalas, acordes, melodías, tonos. Sin mencionar su retención de versos y rimas extraídos de los poetas que leía y transmutarlos, reciclarlos, fusionarlos y situarlos en otras órbitas.

Tal fue su formación cultural y espiritual, bastante ajena a la vida académica, pero no al rigor.

De tal manera, todas las condiciones del mito futuro estaban dadas.

Hijo de su tiempo, confluyen en su creación lírica y musical las tendencias que proporcionó la música country y la tristeza del blues, al que Dylan en una etapa posterior añadió la acometividad y la estridencia del rock; también las corrientes ideológicas de su época, la bipolaridad política, el rechazo de la vida burguesa, la demolición de la vieja América, racista y agresiva con las minorías, y la postulación de un código existencial sin exclusiones, más tolerante y flexible, que no aparta de su senda la elaboración intelectual, ni menos el rigor, pero sí la pedantería, el acartonamiento y el academicismo. Alumbrado por el azar, el vértigo del caos y la embriaguez. En medio de todo eso el legado de Dylan surge con su propuesta poética y también con una bandera, la de la penúltima utopía: el amor. El amor y el arte transformarían la vida, por qué no, como lo habían hecho los románticos, los simbolistas, los surrealistas y lo estaban haciendo en esos instantes los Beatles y los hippies. Los pasaportes eran por supuesto l'amour fou, la borrachera baudeleriana, el desorden sistemático de los sentidos y los alucinógenos.

Interesa consignar la opinión de Dylan sobre la primera etapa de The Beatles:

Eran tan fáciles de aceptar, tan de una pieza... Me acordé de los tiempos en que empezaban a hacerse famosos. Ofrecían intimidad y compañía como ningún otro grupo. Iban a construir un imperio con sus canciones. Me parecía que eso había ocurrido hacía una eternidad. "Do You Want to Know a Secret?”: una perfecta balada ñoña de los cincuenta que nadie habría podido hacer como ellos. Y curiosamente no resultaba cursi. (Crónicas I.)

Dylan enchufó sus instrumentos de los comienzos, explícitamente folk (quizás en exceso puesto que la receptividad de los jóvenes estaba más 
cerca de la órbita del rock y la sicodelia) a los parlantes “Marshall”, y dejó paulatinamente de lado — aunque nunca del todo— esa huella de su máxima adoración, el cantante Woody Guthrie. ¿Caprichos de artista? Cuando Dylan llega a Nueva York, por los sesenta, la música folk era considerada un estilo menor, local, no masivo. El viraje revela más bien el imperativo de todo poeta: arriesgarse, experimentar, fusionar, intentar entrecruzamientos, explorar otros registros en sus letras y en su música. ¿Traición a sus raíces? Sin duda el ansia de expandir su horizonte artístico, puesto que el rock es mucho más universal que la música country. El público suele desear que sus ídolos canten eternamente las mismas canciones y en el mismo estilo, u otras que se les parezcan; de esta forma recibió, en un comienzo, con hostilidad el cambio.

Tiempo después, en la etapa rockera, con la mala voz que Dios le dio para cantar, decidió acompañarse de marginales como él y consiguió ser líder de una troupe de músicos errantes, dedicados a rockear y a blasfemar al unísono con el aullido del poeta beat Allen Ginsberg. Es la etapa de "Bob Dylan and The Band”.

Sin esquivar nada, Dylan fue capaz de alejarse de la pandilla de rockeros que se marcharon demasiado temprano, si bien ya habían dejado una huella penetrante, desde Buddy Holly a Elvis Presley, de Janis Joplin a Jimi Hendrix, de Brian Jones a Jim Morrison. Todos ellos enarbolaron, tal vez con exagerada prontitud, el emblema de la autodestrucción; morir jóvenes, como los elegidos de los dioses. Dylan escapó a fuerza de proponer en su música y en su poética una constante manera de reinventarse, ya que dejaba atrás sin grandes remordimientos una etapa tras otra, estimulado por los vaivenes de su espíritu mucho más que por campañas de prensa y de marketing.

Al respecto dice: "Tenía una esposa e hijos a los que quería más que a nada en el mundo. Intentaba mantenerlos y ahorrarles problemas, pero los moscones de la prensa seguían proclamándome el portavoz, el defensor, incluso la conciencia de una generación” (Crónicas I).

Es paradojal comprobar cómo en una referencia ineludible sobre su persona y su obra, vale decir, sus Crónicas, dé la apariencia de bastante espontaneidad en la gestación y desarrollo de su carrera, si bien, visto desde fuera, no hay tal. Había en esa etapa planificación y una actitud orientada, si no decididamente a la fama, por ejemplo al estilo Elvis Presley, por lo menos al desarrollo de un profesionalismo a toda prueba y un trabajo duro y sostenido.

El espontaneísmo, en la visión que da Dylan de sí mismo, surge en especial en lo relativo a sus primeros discos y en lo relacionado con el 
ofrecimiento de grabar para la transnacional Columbia Records; también en torno al modo de componer algunos de sus grandes hits. Dylan señala específicamente el caso de temas como "Whay Was it You Wanted?” y "Everything is Broken”. De este último dice: "Lo compuse con brochazos inconexos”; y del primero: "Me llevó muy poco tiempo”.

En el clima espiritual de esos años, en Nueva York, influía, de una u otra forma, Allen Ginsberg, el lírico de la desesperación sin salida, el autor de Howl (1956), del manifiesto “La Caída de América”, el que escribió proclamas líricas contra cualquier forma de enrolamiento, el que se refirió a los amantes de toda especie como "Desnudos espectros buscándose entre sí en el silencio”, el que aceptó envejecer, a regañadientes, y se fue de la vida entonando mantras con la próstata en ruinas y el cuerpo tatuado con versos suyos. Ginsberg, el más libre, la reencarnación del patriarca Whitman, quizás la imperfecta fusión entre el vate de las Hojas de Hierba y la dulzura de la reclusa de Amherst, la eterna enlutada con ropas blancas, Emily Dickinson. Ginsberg, el que aseguró, al fin de su aullido, fidelidad a su amante, Carl Solomon, con estas palabras: "Estoy contigo en Rockland, en mis sueños tú caminas chorreando de un viaje por mar sobre la autopista que atraviesa América anegado en lágrimas, hasta la puerta de mi casa de campo en la noche de Occidente”.

\section{Ginsberg, compañero de ruta de Bob Dylan}

Bob Dylan and The Band fue objeto del documental de Martin Scorsese “The Last Waltz” (1976), que grafica en noventa minutos la trayectoria y, en especial, la despedida del grupo de músicos de su líder y vocalista. Sus integrantes, Robbie Robertson, Rich Danko, Levon Helm, Garth Hudson y Richard Manual, fueron rockers on the road, como lo fue el novelista y profeta generacional Jack Kerouac, writer on the road. Allí está el testimonio y la declaración de principios de la inolvidable banda musical en el álbum doble “Bob Dylan. The Band”, la fase más lúcida, digámoslo de una vez, la fase más provocadora de su período electrónico. Acto seguido, los ex componentes de The Band contemplan en la lejanía a su ex vocalista virarse al gospel y pasar, al mismo tiempo, de judío agnóstico a cantante de melodías salvacionistas con aire redentor y atmósfera mesiánica. Dylan, el camaleón, después de caminar durante décadas por la orilla oscura, el irreverente, se vuelve un predicador eléctrico siempre al borde del cortocircuito. No se puede dudar de la sinceridad de su conversión espiritual y tampoco de su refugio en la vida familiar y de que su imagen haya sido 
manipulada por los medios. De hecho en las citadas Crónicas está cerca de la majadería al declarar que no era ni se sentía emblema ni vocero de nada ni de nadie. Tan sólo un cantautor. También revela cierta distancia con las causas políticas e ideológicas de su época. Por otro lado, existe consenso en estimar varios momentos de su extensa carrera como sumamente decaídos, en cuanto a la calidad de su producción musical. Dylan intentó varias veces cambiar su vida y su música y logró una. Quizás la más importante:

No era el maestro de ceremonias de ninguna generación, y la idea generalizada de lo que yo era, debía ser erradicada. Me parecía esencial garantizar mi libertad y la de mis seres queridos. (Crónicas I.)

Y más adelante: "Mi velero de veinte metros de eslora había encallado contra un arrecife en Panamá” (Crónicas I).

Entonces se dedica a sermonear e ingresa a la Comunidad Cristiana de la Viña. Su respuesta musical se encierra en los álbumes “Saved” (1980) y "Shot of Love” (1981).

Ya en el álbum "Highway 61 Revisited” (1965) entonaba: “Abel pregunta dónde quieren que sea la muerte. Dios dice en la autopista 61”.

Al unísono, cómo no, devaneos sexuales, amoríos múltiples y simultáneos, casamiento, hijos (cinco) que ineluctablemente le darían nietos y tratarían de matarlo ${ }^{2}$; amadas vertiginosas que lo reverenciarían y lo destruirían al conocer el lado b de la leyenda, la parte rutinaria y doméstica, y que verían al artista virtuoso empujado a volverse una mercancía, a vender su imagen de rebelde, a integrarse a la gran costumbre transformado en magnate, lo contemplarían marchitarse y amanecer con la garganta en ruinas. Después lo maldecirían, alabarían y perdonarían para permanecer junto a él, reconciliadas y balsámicas. Oh Bob. Ahora es millonario, recibe dinero y fama a raudales de parte del sistema que él cuestiona. Puede comprarlo todo, automóviles, motocicletas; precisamente en uno de esos vehículos padece un severo accidente, en agosto de 1966, a pocos meses de publicar su primer libro Tarántula, un compendio hermético de su visión del mundo. Prosa y poesía a la manera de "Una Temporada en el Infierno” de Rimbaud, contemporáneo del primer libro de poesía de John Lennon, In His Own Write, ambos hojas de ruta para la generación hippie. Diferentes a los postulados de William Burroughs, el "yonqui” histérico y chanta de “Almuerzo Desnudo”, sobrevalorado hasta el absurdo.

\footnotetext{
${ }^{2}$ Se entiende como el asesinato ritual, freudiano, del padre o del abuelo en este
} caso. 
Dylan se borró durante dos años del ambiente artístico tras el porrazo que se dio en la moto, mientras corría contra el viento y contra sí mismo. ¿Intentaría bajar el telón al estilo de James Dean? O tal vez buscaba simplemente respetar la ley. Un rockero no puede envejecer, para el morbo de sus fans debe inmolar su cuerpo, joven e invicto, reventado por las drogas en un hotel cinco estrellas - Bob, no en un cuarto miserable de los que pintó Edward Hopper. Tras ese final épico aparecería en los diarios la foto del occiso, imprescindible para el informe forense, como si hubiese sido despegada del muro de una de las habitaciones espectrales de la película "ParisTexas", de Wim Wenders.

Dylan no pereció así, por suerte, lo sabemos. Sobrevivió para reinventarse y seguir la senda de un cantante pop. Si no murió, por así decirlo, a tiempo para crear una leyenda, se enfrentaba a la tarea no ya de alcanzar la fama, sino de permanecer a lo menos vigente y de no ser avasallado por los medios y, lo peor, de envejecer con dignidad. ¿Rockero cuando cumpla 64 años, y más, como los risibles Rolling Stones?

La razón es que tuvo paciencia para aguardar que sus cenizas se reaglutinaran. Él supo reagruparlas para nacer una y otra vez. Envejeció, cierto, pero con mucha más gloria que pena, dispuesto a entonar "For Ever Young”, sin dar lástima, a cualquier edad.

Si alguna vez quiso transformarse en el reverso de Holden Caulfield, el protagonista de The Catcher in the Rye, que nada quería con el porvenir, rápidamente repudió esa imagen. Bob lo anhela todo con respecto al futuro porque se parece a una highway infinita, una carretera que atraviesa de Nueva York a California, de Jacksonville a Seatle. Mientras tanto, hard rain, Viet Nam, nuevamente atrapado en Mobile con los blues de Memphis, el notable álbum "Nashville Skyline” de 1969 y su famosa ausencia en Woodstock. Digo, the real Woodstock, agosto del 69; no en su segunda parte, de mucho menor impacto artístico y social, en 1994, cuando de las viejas quimeras, del polvo de estrellas que bañó a la multitud hippie mojada por la lluvia purificadora de los tres amaneceres que duró el festival, no quedaban ni cenizas.

Dylan, tal vez como compensación, participó en el revival de Woodstock, en 1994, e interpretó doce canciones. De esa actuación queda un registro en DVD, pero por esos años la generación de Woodstock ya se había integrado al modo de vida que había despreciado.

Cabe decir que su ausencia del magno evento, quizás una de las experiencias antropológicas más inolvidables en la historia de la parte occidental del planeta, terminó por opacar la presencia indesmentible de otros cantantes y estrellas rockeras de la época, que se disolvieron en la decaden- 
cia de sus carreras y en la neblina del olvido. Por ejemplo, y malignamente, John Sebastian, Arlo Guthrie y Richie Havens.

La ausencia de Dylan de Woodstock, enigmática y mitificada en buena medida por el hermetismo del cantante, ¿se debió a ego, a desprecio por el evento, a divismo o a dólares? ¿Deseaba que le pagaran cuando nadie cobró?

Cuesta creerlo. En sus Crónicas despacha el asunto en un par de líneas. Sin más dice: "No estaba allí”.

Curiosamente, antes del magno evento, se había comprado una casa/ granja en Woodstock y tanto fue el asedio de los fans y de la prensa que lo requerían como ícono de diversas causas contestatarias que el cantante, junto con su familia, abandonaron el lugar en busca de privacidad.

También estuvo, y escandalizó, en el festival folk de Newport, en 1965 (esto es, antes de Woodstock), inclinado por esos años a la denuncia social, a la canción protesta y a expresar a los cantantes izquierdistas estadounidenses. Sobre ese escenario enchufó las guitarras a la corriente eléctrica y dejó la tendalada. Salió entre ovaciones, pifias y abucheos, nervioso y desestabilizado.

No sería la primera vez. Dylan ha hecho de la paradoja su arma y de la evolución perpetua su credo, además de desconcertar a plena conciencia a la prensa con declaraciones contradictorias, de afirmación y de rechazo de sus opciones vitales y artísticas. ¿Venganza por la distorsión de su imagen en los años en que intentaba emerger como un cantante distinto, social y poético y fue vapuleado por los medios?

\section{El recital en Santiago}

La llegada al teatro Arena esa tarde de fin del verano estuvo matizada por la ausencia de aglomeraciones y los escasos vendedores que ofrecían camisetas y cintillos ilustrados con el rostro sin glamour, o, más bien, hostil, del artista. — “¿Una camiseta de recuerdo, caballero?” A estas alturas el vocativo es “caballero”, no ha muchos años era “joven”. Se ven hartas canas entre los asistentes, si bien se pueden también advertir tres generaciones, pero no hay histerismos ni aceleración sino una multitud que se prepara para oír, concentrada, al cantante. Los efectivos del Gope no tuvieron trabajo, pocas drogas, nada de desmanes, en una noche cálida de marzo.

Mi localidad es cercana al escenario y cara. A mi lado un señor de más de 70 años llama por su celular, supongo, a una remota amada y le 
informa dónde está, contándole que el domingo pasado asistió, nada menos, que al recital de Iron Maiden en el Estadio Nacional.

Tras una breve espera, se apagan las luces del escenario y la multitud ruge. Algo se agita en mi interior, no puedo evitar que me dé taquicardia, como cuando empezó el recital de Paul Mc Cartney y era mi cita postrera con lo que podía venir a nuestro país de The Beatles, tras la irreversible separación del grupo y la muerte de Lennon. Me pasó lo mismo una vez que vi a Raúl Ruiz en Providencia y a Sam Beckett en un café de la gare de Lyon en París. Pequeños grandes eventos de un mirón.

Tras el griterío catártico, que no excluye las maldiciones y los insultos al pinche gringo cabrón que no pesca a nadie y se cree un dios eléctrico, el público da paso al fervor y el recogimiento. En las primeras canciones más de una adolescente se levanta de su butaca y baila, en su lugar o en los pasillos vacíos - yo hago lo mismo e imito a mi vecino septuagenario, si bien ambos con la discreción que otorgan los años-, pero esos ejemplos no cunden, no da para tanto porque el artista no se comunica con su público, no intenta encenderlo ni menos enardecerlo, perfectamente podría estar solo, en medio de un teatro vacío, iluminado por un cenital, tal vez un sutil signo de Dios. Prefiere optar por el control de calidad, vigila y estimula a sus músicos, verdaderos virtuosos del folk, el blues y el rock, del sonido acústico y del electrónico, antes que condescender con la audiencia, haciéndose el simpático, vendiendo una imagen cálida. El tipo siempre fue un duro, cool a ultranza y no está para coqueteos de última hora. Los fans son una masa móvil que escucha, grita, aplaude, silba. Incluso a veces puede disparar. De hecho, sólo tres canciones fueron frontales y con guitarra eléctrica, del resto del repertorio elegido Dylan toca teclados y enfrenta a sus músicos, no a la muchedumbre hipnotizada. Su profesionalismo y calidad están intactos, desde que comenzó con una guitarra y una armónica. Lo demás es resto, nada de glamour, ni una concesión. Este soy yo.

Como la apatía del cantante con los espectadores es monolítica, no corresponde hacer la ola, ni corear con él las canciones, ni siquiera los hits mundiales, los que todos conocen y si no pueden entender del todo las letras, por lo menos las intuyen o, mala suerte, se quedan con la entonación y el ritmo. Allí están, en versiones remozadas —irreconocibles dirán los detractores de Dylan—, “Just Like a Woman”, “Like a Rolling Stone”, “Lay, Lady, Lay”. De las cientos que ha compuesto, esta última tal vez sea la mejor para este cronista. Todos estos temas interpretados en otro tono, en el caso de "Lay, Lady, Lay” sin la cadencia de balada ni la voz, por única vez de terciopelo, del gestor de una imponente carrera musical, con el chillido áspero que le queda, con el micrófono metido en la boca, nunca cantando bien, pero siempre cantando en forma verdadera. 
No parece necesario explicar o justificar por qué ahora las canta así. ¿Extravagancias sin más o los años se quedaron en su garganta y ya no da los tonos? De cualquier forma, resulta notable comprobar que dejan la impresión de ser otros temas, tan intensos como lo eran en sus primeras versiones. Una vez más Dylan gana y sale con la suya. La decadencia toma el rostro, no la máscara, de la evolución.

Oh, Bob.

En medio del recital, un joven cercano a mi asiento le grita: ¡Judas!, para revivir la célebre anécdota de manera festiva y sin que el cantante pueda escucharlo. Tal como ocurrió el 17 de mayo de 1966 en un concierto que ofreció en Manchester, cuando un espectador, identificado después como Keith Butler, le gritó a Dylan lo mismo: ¡Judas! En esa oportunidad el grito del espectador lo escuchó el ídolo y su respuesta fue: - "No te creo, eres un mentiroso", para acto seguido volverse hacia los integrantes de su banda, diciéndoles: — “Play fucking loud!”, y arrojarle al público el sonido devastador de "Like a Rolling Stone”.

Dylan no se detiene en ningún sueño, no tiene punto de retorno, se puede replegar a una aparente vida conservadora, pero se prepara siempre como un tahúr en su prisión, dispone y ordena las cartas marcadas, las viejas cartas marcadas, para salir una vez más a la superficie. Periódicamente ha tenido colegas que lo interpelan, entre ellos John Lennon, ya separado de los Beatles, cuando exclamaba en un tema musical, tras una larga lista de diatribas contra cuanto falso ídolo se le había cruzado en su trayectoria: "I don’t believe in Zimmerman”. O David Bowie en "Song for Bob Dylan”: "Escúchame, Robert Zimmerman, te he escrito una canción sobre un extraño joven llamado Dylan, con voz de arena y engrudo”.

Dylan también decae, guatea y reitera. Por ejemplo, los álbumes en que se destacan dos o tres temas, siendo benevolentes. Letras crípticas, visiones inaccesibles, la posibilidad de acceso a ese mundo por parte de los auditores es bloqueada por el propio autor, huraño y evasivo. Cada uno de sus fans puede hacer su propia lista, un escrutinio para quemar y salvar álbumes. Gira la rueda, él lo sabe, se tarda muchos años en llegar a ser joven. Hay que haber vivido y recorrido en exceso para alcanzar ese estado.

No obstante, llega 1989 y repunta, y de qué forma, con “Oh Mercy”, producido por Daniel Lanois, sobre cuya colaboración se extiende admirativamente en sus Crónicas.

El brazo sigue caliente, ansía la adrenalina que proporcionan el escenario, el público y el show, es preciso jugar con los medios, necesitarlos y aborrecerlos; rockear aquí y allá, como si todo recomenzara, tocar otra vez con músicos errantes de pueblo en pueblo, como en la etapa del álbum 
“Traveling Wilburys”, acompañado de George Harrison, Roy Orbison, Tom Petty y Jeffe Lynne. Debe botar en el camino la estela del mito, sin cortar la hebra que lleva al laberinto.

\section{Always, on the road}

Se sabe que hizo un programa de radio y ha emprendido, por iniciativa personal, la desclasificación de documentos relativos a etapas de su biografía que resultaban oscuras, ya que, en sus escasas declaraciones a los periodistas, el cantante desplegó velos y fantasías sobre su vida, ironizando y mintiendo a diestra y siniestra. Tras una enfermedad al corazón, pericarditis - los ídolos también enferman-, en 2004 aparece Crónicas, una autobiografía en la que cuenta sus primeros pasos artísticos y vivenciales en el Nueva York de los años sesenta. En estos escritos, que bien pueden ser postreros o el preámbulo de otra etapa, lo que ocultó con celo de avaro, quizás para permitirle a la vida real ocupar un espacio entre el monstruo sagrado y el ídolo, el cantante protesta y el gurú, el profeta y el folklorista del medio oeste, el poeta desgarrado del underground y el esposo y padre de familia que sale de pesca con su prole, muestra una imagen más amable y menos lejana en particular en su relación con quienes lo siguen y admiran, si bien soslaya de manera demasiado evidente el tema de las drogas. Los alucinógenos eternamente estuvieron orbitándolo (everybody must be stoned, solía cantar), sin bastarle el tono frenético de la vida que llevaba, tal vez porque creía que era posible encontrar algo que la volviera más perturbadora y tóxica, más intensa y definitiva, más nostálgica y concluyente.

Una cosa es aquello que él dice de su biografía y de lo experimentado, y otra es lo que cada fan y cada lector puedan interpretar y deducir a la luz, y a la sombra, de otras versiones sobre los hechos de su carrera, extraídos de biografías, de filmes, de reportajes.

Como referente de su compleja y extensa trayectoria artística y biográfica, el fan dylaniano de siempre o el iniciado pueden consultar los tres tomos de Bob Dylan, Años de Juventud, Años de Madurez, Años de Luces y Sombra, editados por el sello Ma non Troppo en 2005. Y del mismo año revisar el largometraje documental, el segundo que le dedica Martin Scorsese, titulado: "No Direction Home”.

\section{Dylan, el alter ego de Robert Zimmerman y viceversa}

Tal vez este monólogo apócrifo sea su monomanía: A fin de cuentas si no morí a tiempo, ni engordé o enloquecí para borrarme como Syd 
Barret, ni me reventaron las drogas como a Hendrix y Presley y me casé con Sara, una ex conejita de Playboy, y tuve hijos, incluso uno que canta, dejé un manantial de sonidos ardientes, de versos, de canciones, de discos. Sin embargo y a pesar de todo eso, no sé qué demonios pinto aquí, cansado, enfermo y pensativo, haciendo dedo en una carretera, un viejo blusero, un cantante folk, un ex ídolo country virado al evangelio del rock, un predicador y cantor de gospel con los labios partidos por los filos de la armónica y las uñas de los pulgares crecidas, sentándome al borde del camino a recordar acordes en la guitarra cuando no pasan vehículos, negando mi parecido con ese remoto cantante pop, para lo cual exhibo mis canas y la cabellera que ralea, presentándome sin esperanzas a un concurso de dobles del old man Dylan, después de agonizar como un patriarca rodeado de nietos que no creerán tan importante la leyenda de su abuelo, ni las mil salidas a escena, ni los cien millones de discos vendidos, tampoco su eterna candidatura al Nobel... - No sabíamos que postulaban por tocar la guitarra y la armónica y entonar con mala voz algunas frases supuestamente poéticas, comentarán.

$\mathrm{O}$ tal vez aparezca un nieto, rebelde e iluso, hirsuto e iluminado, que sienta fastidio hacia un futuro virtual y unos años venideros de reverencia obligada a la sombra del pariente rico y exitoso. Que repudie el vasallaje al poeta protesta, al vago metafísico, al performer ontológico, al abuelo traidor que se pasó a las filas del cristianismo, de quien permanecerán algunos vetustos LPs, Cassettes, CDs o soportes musicales fuera de circulación, con canciones anacrónicas. - “Conservo un frasco azul, dentro de él una oreja y un retrato”, quizás diga. Quedará lo que botó la ola del remoto artista que se pintó sombra en los ojos y se tiñó la cabellera granate. Entonces, con una maleta vieja y una balsámica guitarra de madera, tras reflexionar que dispararle a un mito nunca lo destruye, aterrado ante el porvenir de ordenar las estanterías del negocio del padre y huyendo de un polvoriento pueblo de Minnesota, se largue una vez más a Nueva York a buscar lo mismo de lo mismo de siempre. 